GRASAS Y ACEITES 66 (4)

October-December 2015, e102

ISSN-L: 0017-3495

doi: http://dx.doi.org/10.3989/gya.0238151

\title{
Glycerolysis of sardine oil catalyzed by a water dependent lipase in different tert-alcohols as reaction medium
}

\author{
Á.G. Solaesa ${ }^{a}$, M.T. Sanz ${ }^{\mathrm{a},}$, R. Melgosa ${ }^{\mathrm{a}}$, S.L. Bucio ${ }^{\mathrm{a}}$ and S. Beltrán ${ }^{\mathrm{a}}$ \\ ${ }^{\mathrm{a}}$ Department of Biotechnology and Food Science (Chemical Engineering Section), \\ Pza. Misael Bañuelos s/n, University of Burgos, 09001, Burgos, Spain \\ ${ }^{\square}$ Corresponding author: tersanz@ubu.es
}

Submitted: 10 February 2015; Accepted: 10 June 2015

SUMMARY: The production of monoacylglycerol rich in polyunsaturated fatty acids (PUFA) via enzymatic glycerolysis of sardine oil in a homogeneous system was evaluated. Reactions were conducted in two different tert-alcohols. Based on the phase equilibrium data, the amount of solvent added to create a homogeneous system has been calculated and optimized. The immobilized lipase used in this work was Lipozyme RM IM from Rhizomucor miehei, a water dependent lipase. The amount of water added as well as other reaction parameters were studied to evaluate the optimum conditions for monoacylglycerol obtencion. An initial reactant mole ratio glycerol to sardine oil 3:1, $12 \mathrm{wt} \%$ of water based on glycerol content and $10 \mathrm{wt} \%$ of lipase loading (based on weight of reactants), achieved a MAG yield of around $70 \%$, with nearly $28 \mathrm{wt} \%$ PUFA, with low free fatty acid content (lower than $18 \mathrm{wt} \%$ ).

KEYWORDS: Fish oil; Glycerolysis; Lipase; Monoacylglycerol; Rhizomucor miehei; Tert-alcohols

RESUMEN: Glicerolisis de aceite de sardina catalizada por una lipasa dependiente de agua en diferentes tert-alcoholes como medio de reacción. En este trabajo se ha estudiado la producción de monoacilglicéridos, ricos en ácidos grasos poliinsaturados (AGPI), mediante glicerolisis enzimática de aceite de sardina. La reacción se ha llevado a cabo en dos tert-alcoholes para conseguir de esta forma un medio homogéneo de reacción. La cantidad de disolvente añadida al medio de reacción se ha optimizado y calculado en base al equilibrio de fases de los componentes del sistema. La lipasa empleada como biocatalizador ha sido la enzima inmovilizada Lipozyme RM IM de Rhizomucor miehei, una lipasa dependiente de agua. Se ha estudiado el efecto de distintos parámetros cinéticos, así como de la cantidad de agua añadida al medio de reacción, en la producción de monoacilglicéridos. De los resultados obtenidos, se puede concluir que, para una relación molar inicial de reactantes glicerol:aceite de sardina de $3: 1$, un $12 \%$ en peso de agua en base al glicerol y un $10 \%$ en peso de lipasa, en base al peso de reactantes; se puede llegar a conseguir un rendimiento en monoacilglicéridos alrededor del $70 \%$ en peso, con casi un $28 \%$ en peso de AGPI y un bajo contenido en ácidos grasos libres (menor del $18 \%$ en peso).

PALABRAS CLAVE: Aceite de pescado; Glicerolisis; Lipasa; Monoacilglicéridos; Rhizomucor miehei; Tert-alcoholes

Citation/Cómo citar este artículo: Solaesa ÁG, Sanz MT, Melgosa R, Bucio SL, Beltrán S. 2015. Glycerolysis of sardine oil catalyzed by a water dependent lipase in different tert-alcohols as reaction medium. Grasas Aceites 66 (4): e102. doi: http://dx.doi.org/10.3989/gya.0238151.

Copyright: (C) 2015 CSIC. This is an open-access article distributed under the terms of the Creative Commons Attribution-Non Commercial (by-nc) Spain 3.0 Licence. 


\section{INTRODUCTION}

Marine raw materials are rich sources of omega-3 PUFA, especially eicosapentaenoic acid (EPA) and docosahexaenoic acid (DHA). The health benefits of omega-3 PUFA have been demonstrated (Nichols et al., 2014; Sidhu, 2003). Fish oil can be extracted from the whole fish or from its by-products such as skin or viscera. The use of these by-products is attractive from an economic point of view. Fish oil is a valuable ingredient in its natural form or as different lipid derivatives. Among these compounds, monoacylglycerols (MAG) and diacylglycerols (DAG) have found extensive applications in food and pharmaceutical products (Blanco et al., 2007; Hernandez, 2014; Kim et al., 2006). MAG are nonionic amphiphilic molecules with excellent emulsifying properties. Commercial food-grade MAG are usually manufactured by chemical glycerolysis of fats and oils. In these reactions high temperatures $\left(220-250{ }^{\circ} \mathrm{C}\right)$ and inorganic alkaline catalysts are used. These chemical and physical processes are not suitable for heat-sensitive oils and fats rich in polyunsaturated fatty acids such as fish oils. Due to the disadvantages of conventional glycerolysis, the enzymatic process is an attractive alternative method for polyunsaturated MAG production because the reaction can be carried out under mild conditions (Bornscheuer, 1995).

The overall glycerolysis reaction is given by Equation 1 (Feltes et al., 2013). This reaction takes place in two consecutive steps. In the first step (Eq. 2), the transfer of a fatty acid (FA) from triacylglycerols (TAG) to glycerol gives one molecule of MAG and one molecule of DAG. In the second step (Eq. 3), two molecules of MAG are formed by the transfer of an FA from DAG to glycerol:

$\mathrm{TAG}+2 \mathrm{GLY} \rightleftarrows 3 \mathrm{MAG}$

$\mathrm{TAG}+\mathrm{GLY} \rightleftarrows \mathrm{MAG}+\mathrm{DAG}$

$\mathrm{DAG}+\mathrm{GLY} \rightleftarrows 2 \mathrm{MAG}$

To avoid external mass transfer limitations due to the immiscibility between reactants, oil and glycerol, a solvent can be added to the system to create a homogenous phase. In the literature, other studies about solvent-free glycerolysis have been found (Fregolente et al., 2008; Torres et al., 2002; Weber et al., 2004), but the product conversion was quite low due to the limited contact between the reactants.

According to Damstrup et al. (2005), tert-butanol and tert-pentanol resulted in excellent solvents to carry out these reactions. Their $\log \mathrm{P}$ values $(0.35$ and 0.89 , respectively) indicate both hydrophilic and hydrophobic characteristics. Moreover, these alcohols do not involve reactions with fatty acids, most likely due to their tertiary structure, which exerts strong steric hindrance to the enzyme. The liquid-liquid equilibrium (LLE) data of these systems (sardine oil + glycerol + tert-alcohols) have been determined in a previous work (Solaesa et al., 2013). LLE data help to optimize the amount of solvent needed to create a homogeneous reaction system, since by increasing the amount of solvent in the reaction medium, the concentration of substrates at the interface decreases, leading to lower reaction rates.

The most widely used lipases to carry out enzymatic glycerolysis reactions are from Candida antarctica (Novozym 435), Pseudomonas fluorescens (IM-AK), Thermomyces lanuginose (Lipozyme TL IM) and Rhizomucor miehei (Lipozyme RM IM) (Kristensen et al., 2005). The carrier supports of Lipozyme TL IM and RM IM are hydrophilic. In the presence of a hydrophilic support, the polar reactant, glycerol, is attracted to the hydrophilic support and hence the reaction could be inhibited. On the contrary, the carrier support of Novozym 435 is hydrophobic, therefore glycerol does not inhibit the reaction (Yeoh et al., 2009).

Several authors use Novozym 435 as biocatalyst to carry out the glycerolysis reaction due to its highest activity (Pawongrat et al., 2008; Yang et al., 2005a; Yeoh et al., 2009). However, this enzyme is an expensive lipase compared with other commercial lipases. On the other hand, natural omega-3 PUFA and specifically DHA and DPA are mainly found in fish oil at the sn-2 position of the glycerol backbone (Solaesa et al., 2014). These fatty acids are better adsorbed as monoacylglycerols esterified at the secondary position. Therefore, the use of 1,3 specific lipase would be more convenient than the use of a nonspecific one, such as Novozym 435. However, even when using sn-1,3 specific lipases, undesirable and unavoidable side reactions of acyl migration can occur to some extent. Acyl migration depends on several parameters, namely reaction temperature, lipase loading, immobilization supports, water content and water activity, solvent type and reaction system (Xu, 2000; Xu, 2003).

Some commercially available 1,3 specific lipases are from Rhizopus oryzae, Thermomyces lanuginose or Rhizomucor miehei. Rendón et al. (2001) studied the glycerolysis of triolein with Lipozyme RM IM and tert-pentanol as reaction medium. They found that water activity was an important factor in lipase activity. Some water is needed in the reaction medium to maintain the catalytic active conformation of the enzyme (Wongsakul et al., 2003). However, an excess of water causes acyl migration which leads to a decrease in the MAG yield (Singh et al., 2012).

In this work the enzymatic glycerolysis of sardine oil in two different tert-alcohols (tert-pentanol and tert-butanol) as reaction media has been studied. The commercial 1,3-specific lipase Lipozyme RM IM (from Rhizomucor miehei) immobilized on a 
macroporous anion-exchange resin has been used as biocatalyst. In addition to its specificity, Lipozyme RM IM is cheaper than the non-specific Novozym 435 commonly used in enzymatic glycerolysis (Zhong et al., 2009). The effect of water content in the reaction medium has been analyzed since it affects the lipase activity and therefore the reaction rate and MAG yield. This way, optimum water content has been determined by taking the MAG yield and the FFA formation into account.

\section{MATERIALS AND METHODS}

\subsection{Materials}

The sn-1,3 specific lipase Lipozyme RM IM (immobilized Rhizomucor miehei lipase) was obtained from Sigma Aldrich. The water content of Lipozyme RM IM was $3.5 \pm 0.3 \%$ as determined by Karl-Fisher titration with a Mitsubishi CA-20 moisture meter in triplicate. Glycerol was also purchased from Sigma Aldrich with a purity of $\geq 99.5 \%$ and a water content of $0.04 \pm 0.01 \%$. Tert-butanol and tert-pentanol were purchased from Merck with a purity of $\geq 99 \%$ and a water content of $0.298 \pm 0.033 \%$ and $0.065 \pm 0.023 \%$, respectively. Refined sardine oil was kindly provided by Industrias Afines S.L. (Spain).

The standards of MAG, DAG, FFA and fatty acid methyl ester (FAME) for the chromatography analysis were purchased from Sigma. All other solvents and reagents were of analytical or chromatographic grades from VWR.

\subsection{Enzymatic Glycerolysis of Sardine Oil}

The mixture of sardine oil, glycerol, water and tert-alcohol (TB or TP) was incubated at $50{ }^{\circ} \mathrm{C}$ in a water bath with orbital agitation in different vials. The reaction was initiated by the addition of the lipase. The enzyme loading was $10 \mathrm{wt} \%$, based on the total amount of substrates. At different time intervals, the corresponding vial was withdrawn and filtered through a microfilter $(0.45 \mu \mathrm{m}$, Sartorius RC) to stop the reaction by removing the lipase. All samples were stored at $-18^{\circ} \mathrm{C}$ prior to analysis. The samples were analyzed at least in duplicate.

The conditions of the kinetic experiments performed in this work are presented in Table 1. The amount of water added to the system varied in the range of 4 to $30 \mathrm{wt} \%$, based on glycerol weight, in the reaction medium. The amount of tert-alcohol added was calculated on the basis of previous studies on liquid liquid equilibrium for the glycerolysis systems of sardine oil with the two tert-alcohols as reaction medium (Solaesa et al., 2013). Table 2 shows the amount of solvent added in other glycerolysis systems found in the literature to avoid mass transfer limitation due to the immiscibility of oil
TABLE 1. Glycerolysis reaction conditions (mole ratio of substrates, water content and amount of tert-alcohol added to the system) at $50{ }^{\circ} \mathrm{C}$ (Solaesa et al., 2013).

\begin{tabular}{ccccccc}
\hline $\begin{array}{l}\text { Reactants mole } \\
\text { ratio (glycerol:oil) }\end{array}$ & $\begin{array}{c}\text { Tert-alcohol } \\
\text { (wt \%) }\end{array}$ & \multicolumn{4}{c}{$\begin{array}{c}\text { Amount of water } \\
\text { (wt \% of glycerol) }\end{array}$} \\
\hline $1: 1$ & 50 & 4 & 7 & 10 & 20 & 30 \\
$3: 1$ & 60 & - & 7 & 10 & 12 & 24 \\
$5: 1$ & 65 & - & 10 & 12 & 17 & 28 \\
\hline
\end{tabular}

and glycerol. Compared to the amount of solvent added in this work (Table 1), it can be observed that in most cases the amount of solvent added is not optimized due to an excess or deficiency from the beginning of the reaction.

\subsection{Determination of reaction products}

The neutral lipid profile (MAG, DAG, TAG and FFA) was analyzed by a normal-phase high performance liquid chromatography (NP-HPLC). The chromatographic apparatus consisted of an HPLC system (Agilent 1200) formed by a quaternary pump and an auto-injector. The chromatographic separation of the compounds was carried out at room temperature with a Lichrospher Diol column $(5 \mu \mathrm{m}, 4 \mathrm{~mm} \times 250 \mathrm{~mm})$ and detection was performed in an evaporative light scattering detector (Agilent 1200 series) at $35^{\circ} \mathrm{C}$ and $0.35 \mathrm{MPa}$. Gradient elution was achieved by mobile phases A (isooctane) and B (methyl tert-butyl ether:acetic acid =99.9:0.1, v/v). The course of the gradient was as follows: first, solvent $\mathrm{A}$ was flowing for $1 \mathrm{~min}$, after that, solvent B was added in three steps, at up to $10 \%$ in $10 \mathrm{~min}$, to $44 \%$ in $22 \mathrm{~min}$ and to $100 \%$ in $30 \mathrm{~min}$. Subsequently, solvent B was decreased to $0 \%$ in $17 \mathrm{~min}$ to return to the initial conditions. Finally, the stationary phase was rinsed with solvent A for $2 \mathrm{~min}$. Injection volumes of $10 \mu \mathrm{l}$ and the elution flow-rate of $1 \mathrm{ml} / \mathrm{min}$ were used in all experiments. The different family of compounds were identified and quantified by using calibration curves of the corresponding standard compounds of DAG, a mixture of dipalmitin (26657-95-4) and diolein (25637-84-7), MAG, a mixture of 1-monopalmitin (542-44-9), 1-monoolein (111-03-05), 2-monoolein (3443-84-3) and monodocosahexaenoin and FFA, a mixture of oleic acid (112-80-1) and palmitic acid (57-10-3) in tert-pentanol. In the case of TAG, the calibration curve used was made with the refined sardine oil (TAG $\geq 99 \%$ ) because the response factor of the oil as a complex mixture of TAG was very different than the pure standards of TAG. The calibration method has been validated by analyzing two different samples formed by MAG, DAG and FFA standards and sardine oil in the concentration range 
TABLE 2. Amount of tert-alcohol added in other glycerolysis systems found in the literature.

\begin{tabular}{lllll}
\hline \multicolumn{1}{c}{ Oil } & Mole ratio (glycerol:oil) & \multicolumn{1}{c}{$\mathbf{T}\left({ }^{\circ} \mathbf{C}\right)$} & $\%$ wt of tert-alcohol & \multicolumn{1}{c}{ Reference } \\
\hline Palm & $8: 1$ & 45 & $82 \%$ of TB & (Majid et al., 2012) \\
Olive & $6: 1,3: 1,0.8: 1,0.5: 1.5$ & $40,55,70$ & $44 \%$ of TB & (Voll et al., 2011) \\
Olive & $9: 1,6: 1,3: 1,1: 1$ & $40,55,70$ & $44 \%$ and $80 \%$ of TB & (Krüger et al., 2010) \\
Triolein & $2: 1$ & 40 & $93 \%$ of TP & (Rendón et al., 2001) \\
\hline
\end{tabular}

of the corresponding calibration curves to obtain good reliability.

The analysis of remaining glycerol was performed using High-Temperature Gas Chromatography (HTGC). The method and the calibration procedure were previously developed (Solaesa et al., 2013).

\subsection{Fatty acid profile of MAG fractions}

The MAG fraction separated by NP-HPLC under the optimal reaction conditions with both solvents was collected according to its retention time. Separations were repeated at least six times to obtain enough sample for the fatty acid profile analysis. The fractions were stored in special flasks to evaporate the solvent under vacuum using a rotary evaporator (Heibolph VV2000) at $40{ }^{\circ} \mathrm{C}$. Then the samples were transferred to screw-capped tubes to carry out the derivatization for conversion to methyl esters by the AOAC method (AOAC Official Method $991.39,1995)$ and subsequent analysis by Gas Chromatography with an Agilent gas chromatograph (6890N Network GC System) equipped with a flame ionization detector (FID). A fused silica capillary column (OmegawaxTM-320, $30 \mathrm{~m} \times 0.32 \mathrm{~mm}$ i.d.) was used. The separation was carried out with helium $\left(1.8 \mathrm{ml} \cdot \mathrm{min}^{-1}\right)$ as carrier gas. The column temperature was programmed starting at a constant value of $180^{\circ} \mathrm{C}$ during $20 \mathrm{~min}$, heated to $200^{\circ} \mathrm{C}$ at $1^{\circ} \mathrm{C} \cdot \mathrm{min}^{-1}$, held at $200{ }^{\circ} \mathrm{C}$ during $1 \mathrm{~min}$, heated again to $220^{\circ} \mathrm{C}$ at $5^{\circ} \mathrm{C} \cdot \mathrm{min}^{-1}$ and finally held at $220^{\circ} \mathrm{C}$ for $20 \mathrm{~min}$. A split injector (50:1) at $250{ }^{\circ} \mathrm{C}$ was used. The FID was also heated at $250^{\circ} \mathrm{C}$. The injection volume was $1 \mu \mathrm{L}$. Most of the fatty acid methyl esters were identified by comparison of their retention times with those of chromatographic standards (Sigma Chemical Co.). The calibration procedure was previously developed and quantification was possible by relating the peak areas to the area of an internal standard (methyl tricosanoate) as indicated by the AOAC method (AOAC Official Method 991.39, 1995).

\subsection{Isomeric separation of reaction products}

The separation of the different acylglycerols was performed by TLC on silica gel plates (Silica gel 60 F254, Merck). A similar method of Jin et al. (2011) was used to visualize sn-1(3) and sn-2-MAG isomers. The plates were impregnated by immersion in a hydro-ethanolic solution $(50 \%, \mathrm{v} / \mathrm{v})$ of boric acid $(1.2 \mathrm{wt} \%)$. Afterwards, they were activated by heating at $100{ }^{\circ} \mathrm{C}$ for $15 \mathrm{~min} .20 \mu \mathrm{L}$ of the reaction mixture were directly spotted on the TLC plate. The plates were then developed in chloroform/acetone/ methanol $(95: 4.5: 0.5, \mathrm{v} / \mathrm{v} / \mathrm{v})$. Spots of each lipid were visualized with a UV lamp.

\section{RESULTS AND DISCUSSION}

In a first step, the glycerolysis of sardine oil using both tert-alcohols as reaction media, but without any enzyme as catalyst was performed. The experimental conditions were the following: $50^{\circ} \mathrm{C}$, initial mole ratio glycerol to oil 3:1 and solvent to substrates ratio of $1.2: 1 \mathrm{w} / \mathrm{w}$. It was observed that the glycerolysis reaction does not present an autocatalytic behavior since under these experimental conditions the observed reaction rate was almost zero. Yang et al. (2005b) showed that at room temperature and without the presence of any catalyst, the reaction rate for this reactive system is generally very slow, and the substrates may need weeks to be transformed into the products. The same behavior was also verified by Krüger et al. (2010) at $70{ }^{\circ} \mathrm{C}$.

In this work, further glycerolysis experiments were performed at $50{ }^{\circ} \mathrm{C}$, solvent to substrates ratio of $1.2: 1 \mathrm{wt} / \mathrm{wt}$ and $10 \mathrm{wt} \%$ of Lipozyme RM IM loading at different glycerol to oil mole ratios (1:1, $3: 1$ and 5:1). In these experiments no water was added and it was observed that the glycerolysis reaction did not occur. This might be because the carrier of Lipozyme RM IM is hydrophilic and the glycerol, as a hydrophilic substrate, can be preferably adsorbed onto the support depraving the essential water from the enzyme. Therefore, the water content in the reaction medium must be an essential factor in the activity of Lipozyme RM IM. In the next section the effect of water addition in the glycerolysis system catalyzed by Lipozyme RM IM will be presented and discussed.

\subsection{Effect of water content}

As has been already mentioned, the carrier support of Lipozyme RM IM is hydrophilic. In the presence of a hydrophilic support, the tert-alcohol and mainly glycerol $\left(\mu=2.617, \log \mathrm{P}=-1.84\right.$ and $\left.\varepsilon\left(23^{\circ} \mathrm{C}\right)=41.01\right)$ (Riddick et al., 1986) can be preferably adsorbed onto 
the support. Due to the hydrophilic nature of the reaction medium, some essential water from the lipase can be removed. Therefore, it is important to determine the optimal water content in the reaction medium since it affects lipase activity and therefore the reaction rate and yield product. On the other hand, when the water content is too high it does not enhance the MAG yield resulting in an increase in by-product formation, such as FFA (Zhong et al., 2009). Therefore water control is important to ensure enzyme activity as well as to minimize hydrolytic side reactions.

First, some preliminary experiments were carried out to study the effect of the polarity medium in the retention of titrable water by the enzyme. The moisture of different reaction media (tertalcohol+glycerol+sardine oil) at different reactant mole ratio glycerol:oil, from 1:1 to $6: 1$ was first determined. Then, Lipozyme RM IM with a known amount of titrable water was added at $10 \% \mathrm{w} / \mathrm{w}$ based on the weight of the reactants. After 24 hours of contact time at $50{ }^{\circ} \mathrm{C}$ (time enough to reach sorption equilibrium) the water content of the reaction medium was again determined. Total titrable water retention by Lipozyme RM IM was evaluated according to Equation 4:

$\%$ water retention $=\left(1-\frac{\text { increase of water in the retention medium }}{\text { amount of titrable water of the lipase }}\right) \cdot 100$

Figure 1 shows the titrable water retention by Lipozyme RM IM in both tert-alcohols studied in this work. By increasing the amount of glycerol in the reaction medium (higher glycerol: oil mole ratio) more water is removed from the lipase surrounding. This can be related to the higher polarity of the reaction medium when increasing the glycerol content.

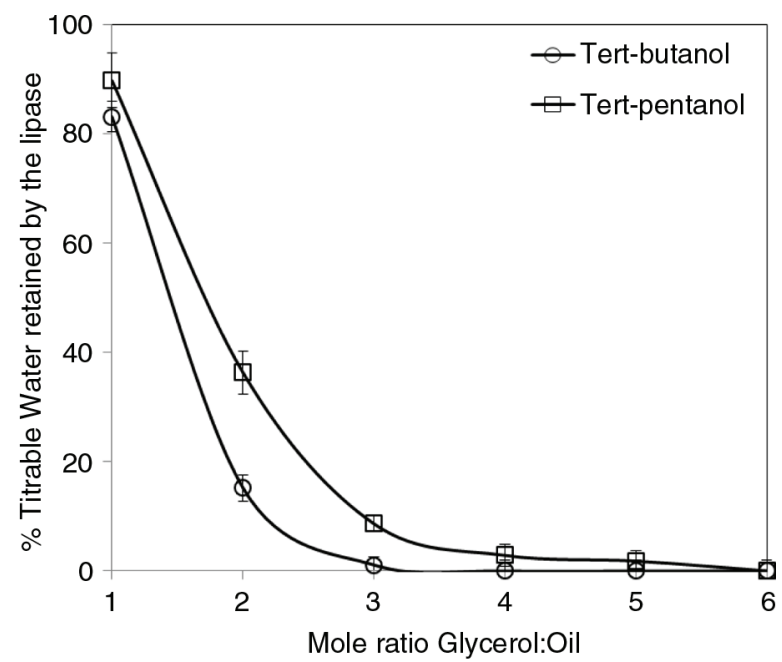

FIGURE 1. Titrable water retention by Lipozyme RM IM at different initial molar ratio glycerol:oil in both tert-alcohols. Lines are to guide the eye.
This behavior could explain previous results on glycerolysis kinetics where no reaction took place even in the presence of Lipozyme RM IM as catalyst, proving that this lipase is water-dependent. When comparing both tert-alcohols, tert-butanol is more hydrophilic than tert-pentanol $(\log \mathrm{P}=0.35$ and $\log$ $\mathrm{P}=0.89$, respectively), therefore a tert-butanol medium deprives more water from the enzyme than a TP medium under the same conditions. Consequently, TB as reaction medium would need more added water than TP to obtain similar results under the same conditions.

The effect of water content in the reaction medium on MAG and FFA yield at three different initial reactant mole ratios (glycerol:oil), 1:1, 3:1 and $5: 1$, was studied at $50^{\circ} \mathrm{C}$ by varying the amount of water added to the reactive system in the range of $4-30 \mathrm{wt} \%$ of water based on glycerol weight (Table 1). Figure 2 shows the MAG and FFA content obtained by using tert-butanol and tert-pentanol as reaction medium after $20 \mathrm{~h}$ reaction time. As a general trend, MAG yield increased with the increase of water content in the reaction medium up to a maximum. The highest yield of MAG was obtained by adding around $7-17 \mathrm{wt} \%$ of water, depending on the substrate mole ratio. For instance at a mole ratio of $1: 1$ the percentage of water added to yield a maximum in the MAG production was around $7 \mathrm{wt} \%$ in $\mathrm{TP}$ as reaction medium and $10 \mathrm{wt} \%$ in TB as reaction medium. This behavior agrees with the results presented in Figure 1. However at a mole ratio of 5:1 the optimum percentage of water added for both tert-alcohols was of the same order, around $17 \mathrm{wt} \%$. This could be explained by taking into account that at such high mole ratio most of the essential water of the enzyme has been deprived (Figure 1) and the effect of solvent is less pronounced. An increase in the amount of water in the reaction medium also leads to an increase in the FFA content, caused by higher hydrolysis rates due to the higher content of water. At a mole ratio of 3:1 FFA content in the reaction medium increased from 5.3 to $32.5 \mathrm{wt} \%$ when increasing the amount of added water from 7 to $24 \mathrm{wt} \%$, respectively. Therefore an optimal amount of water to be added to the reaction medium taking into account the MAG yield and the FFA formation at the different mole ratios glycerol:oil does exist. In addition, mass transfer limitations of the lipophilic substrate, the sardine oil, from the reaction medium to the vicinity of the enzyme can become important at high water content since, as described in the literature (Cheirsilp et al., 2007; Zhong et al., 2009), an excess of water can surround the particles instead of forming a thin mono-hydration layer for catalytically-active conformation. Zhong et al. (2009) found that the highest yield of MAG was obtained when $10 \mathrm{wt} \%$ of water was added to the glycerolysis system of soybean oil with Thermomyces lanuginosus lipase and TB/Isopropanol (80:20) as solvent system. 

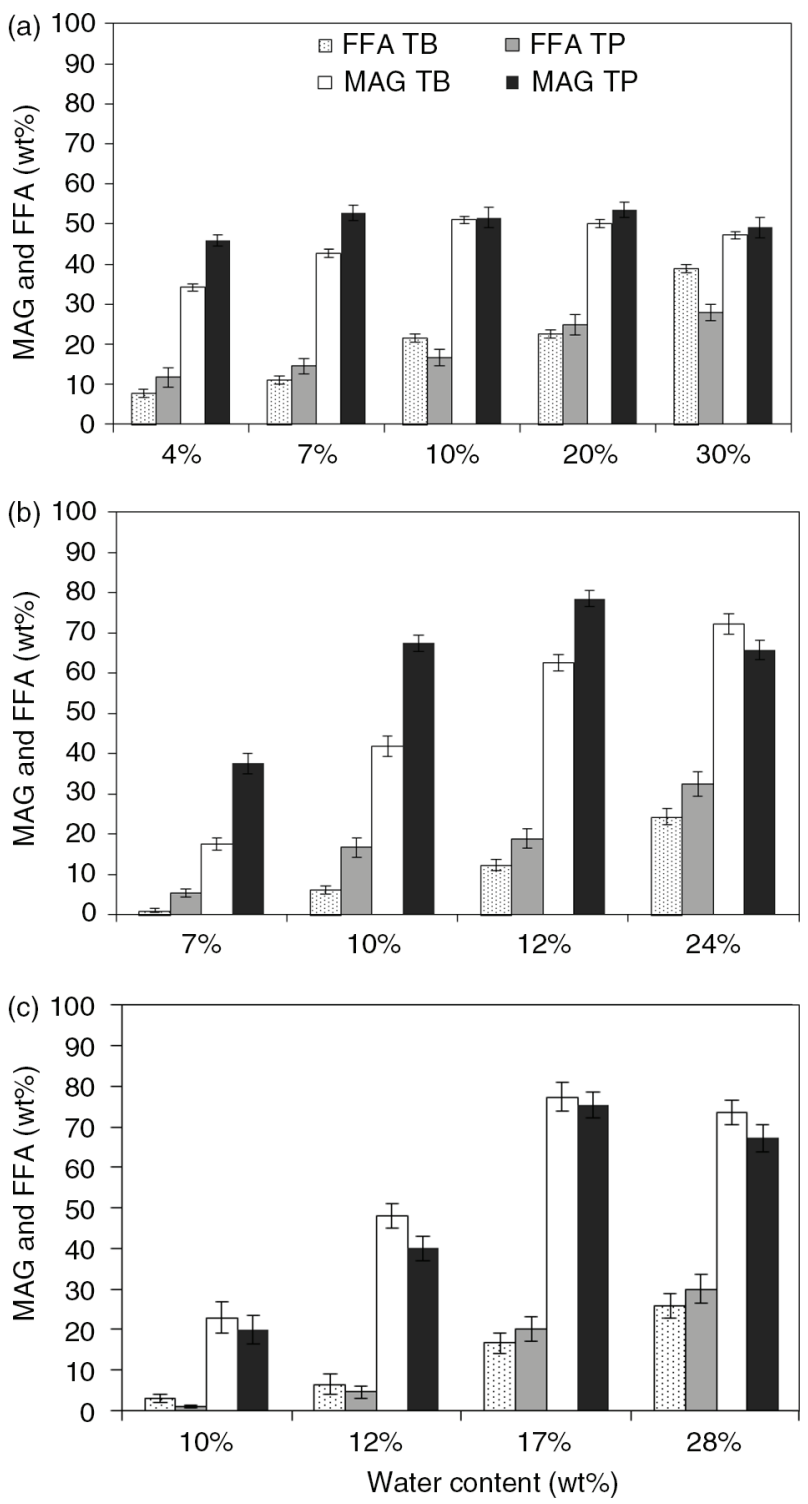

FIGURE 2. Effect of water content, based on glycerol weight, on glycerolysis of sardine oil at different initial mole ratio glycerol:oil (a) 1:1 (b) 3:1 and (c) 5:1. Reaction conditions: $10 \mathrm{wt} \%$ Lipozyme RM IM (based on substrates), $50{ }^{\circ} \mathrm{C}$ at $20 \mathrm{~h}$.

\subsection{Effect of substrate mole ratio}

Substrate mole ratio, glycerol:oil, has different effects on lipase-catalyzed glycerolysis. According to the equilibrium law, an increase in the glycerol content will shift the equilibrium towards MAG production. In the literature, it has been also described that glycerol can act as an effective stabilizer against thermal and solvent de-activation (Zhong et al., 2009). However, in the case of water-dependent lipases, the glycerol content can also directly affect the lipase activity due to its influence on the polarity of the reaction medium.
The effect of glycerol:oil mole ratio on the reaction rate was studied at $50{ }^{\circ} \mathrm{C}, 10 \mathrm{wt} \%$ of lipase loading, by varying the mole ratio from $1: 1$ to $5: 1$. Figure 3 shows the MAG profile at the different glycerol:oil mole ratio and at a high content of water added (from 24 to $30 \mathrm{wt} \%$ based on the glycerol content) for both tert-alcohols. By increasing the initial substrate mole ratio, MAG equilibrium conversion also increases. For instance MAG content at a mole ratio of $1: 1$ is around $50 \%$ in tert-butanol, while it reaches a maximum of $75 \%$ at a mole ratio of $5: 1$. However, it must be highlighted that there is little difference in MAG content at 3:1 and 5:1 glycerol:oil mole ratio. Based on these results, a glycerol:oil mole ratio of 3:1 was selected as optimum in the present study. This result agrees with some previous studies on glycerolysis of different types of oils. Zhong et al. (2009) selected 3.5:1 as optimum glycerol:soybean oil mole ratio, in their study on the glycerolysis reaction in a mixture of TB/Isopropanol (80:20) as reaction medium. Pawongrat et al. (2007) used MTBE as solvent and showed that the optimum mole ratio of glycerol to tuna oil for MAG production was 3:1.

\subsection{Effect of solvent type}

Solvents can have different effects on reaction systems. They help to create a homogeneous reaction system and improve mass transfer by reducing the viscosity of the reaction medium. When polar solvents are used, essential water from the lipase can be removed leading to a decrease in the lipase activity. In this work two tertiary alcohols, tert-butanol and tertpentanol, have been considered as reaction media. $\log \mathrm{P}$ is one of the most widely used parameters to correlate the solvent properties to the enzyme activity. Taking into account the $\log \mathrm{P}$ of TB and TP $(0.35$ and 0.89 respectively), TB is slightly more hydrophilic than TP; therefore water retention by the lipase will be lower when using TB as reaction medium and slower reaction rates can be expected.

Figure 4 shows the effect of both tert-alcohols on the time course of the glycerolysis of sardine oil under the same reaction conditions at different amounts of water added to the reaction medium. As expected, the reaction rates in TB were slower than in TP. Nevertheless, MAG equilibrium yield was of the same order for both tert-alcohols.

\subsection{MAG production under optimal conditions}

Based on the results presented in this work, the optimal conditions for MAG production with $10 \mathrm{wt} \%$ loading of Lipozyme RM IM, based on substrate weight, at $50{ }^{\circ} \mathrm{C}$ were the following: initial mole ratio glycerol:oil 3:1, water content in glycerol $12 \mathrm{wt} \%$ and $60 \mathrm{wt}^{\%} \%$ of the corresponding tert-alcohol to provide a homogeneous medium. Mole ratio higher than 3:1 does not lead to an increase in MAG yield (Figure 3 ). 

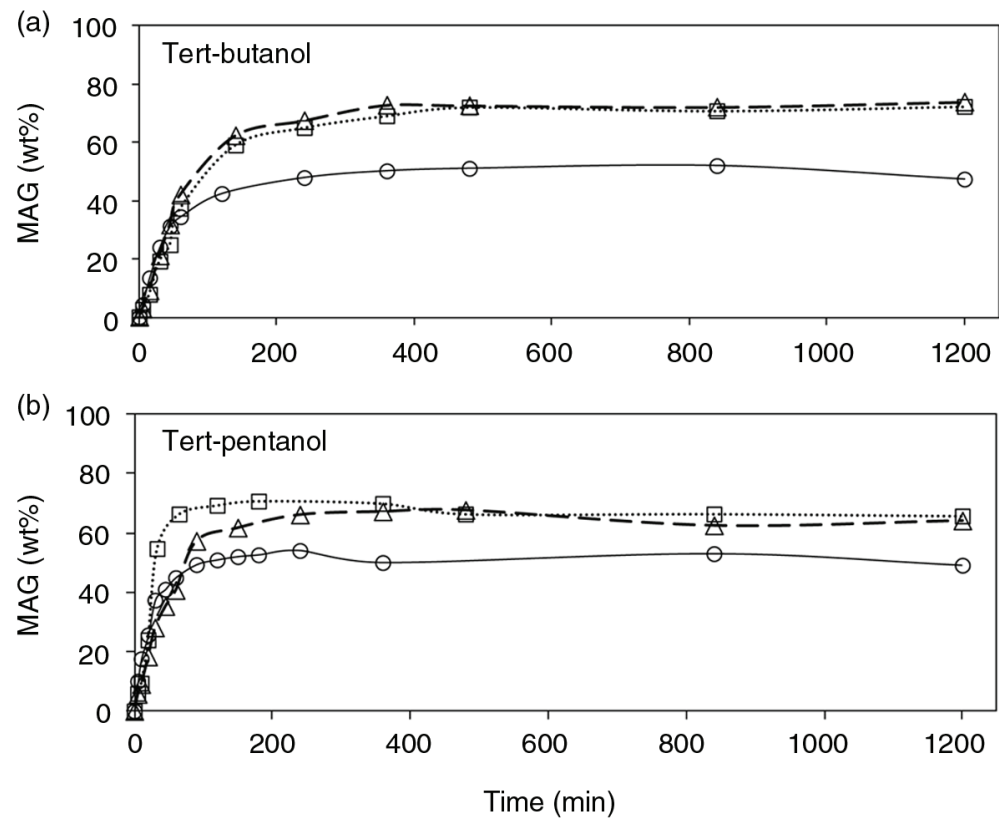

FIGURE 3. Effect of substrate mole ratio on the time course of glycerolysis of sardine oil (a) TB, (b) TP at different initial mole ratio glycerol:oil (-o-) 1:1, (- --) 3:1, (- $\Delta-$-) 5:1. Reaction conditions: $10 \mathrm{wt} \%$ Lipozyme RM IM (based on oil and glycerol), $50{ }^{\circ} \mathrm{C}$ and $24-30 \mathrm{wt} \%$ of added water based on glycerol weight (see Figure 2).

At this mole ratio, a maximum in MAG yield (around $78 \mathrm{wt} \%$ ) in TP is reached at $12 \mathrm{wt} \%$ of water added, based on glycerol weight, with less than $20 \mathrm{wt} \%$ of FFA (Figure 2). The time course of the glycerolysis of sardine oil for all the compounds in both tert-alcohols under the optimal conditions is presented in Figure 5.

Figure $5 \mathrm{a}$ and $5 \mathrm{~b}$ represent the glycerolysis course in TB and TP respectively. From Figure 5a it can be observed that the MAG content in TB as reaction medium was higher than $65 \mathrm{wt} \%$ after 20 hours of reaction time. At this reaction time the TAG content in the reaction medium was still about $20 \mathrm{wt} \%$. DAG production slightly increased during the first 4 hours and then it remained relatively constant at around $7 \mathrm{wt} \%$. At the beginning of the reaction, FFA formation is nearly negligible and then it rose slowly up to $10 \mathrm{wt} \%$.

From Figure $5 \mathrm{~b}$ it can be observed that the reaction rate was faster in TP than in TB. TAG decreased sharply during the first $2 \mathrm{~h}$ and then the reaction rate became slower. MAG content also increased quickly during the first $2 \mathrm{~h}$ reaching a value of $60 \mathrm{wt} \%$. From this time on, the reaction rate slowed down and MAG content reached a maximum value of $78 \mathrm{wt} \%$. DAG production achieved a maximum at $2-3 \mathrm{~h}$ reaction time and then its content steadily decreased. FFA formation is also faster in TP than in TB.

The FA profile of the different MAG fractions obtained under the optimal conditions was analyzed by GC. MAG fractions at two different reaction times ( $4 \mathrm{~h}$ and $20 \mathrm{~h}$ ) were separated by HPLC and collected to determine their fatty acid profiles (Table 3). The MAG content in TP as reaction medium at the selected reaction times, $4 \mathrm{~h}$ and $20 \mathrm{~h}$, was $70 \mathrm{wt} \%$ and $77 \mathrm{wt} \%$, respectively. On the other hand, in TB as reaction medium, the MAG content was 22 and $66 \mathrm{wt} \%$ at 4 and 20 hours, respectively. A much longer reaction time is needed in TB than in TP to reach the same MAG percentage in the reaction medium.

From Table 3 a similar fatty acid profile of the MAG fraction obtained in tert-butanol at $20 \mathrm{~h}$ reaction time was observed ( $66 \mathrm{wt} \%$ of MAG) as in tertpentanol at $4 \mathrm{~h}$ of reaction time ( $70 \mathrm{wt} \%$ of MAG). Although the reaction rate is slower in TB, it could be concluded that Lipozyme RM IM would behave qualitatively in the same way according to MAG conversion and fatty acid profile in both tert-alcohols. Figure 6 represents the different types of FA in the MAG fractions as a function of the MAG content in the reaction medium for both tert-alcohols. The PUFA content in the MAG fraction increased when the conversion degree also increased; while monounsaturated FA (MUFA) and saturated FA (SFA) decreased.

TLC analyses have been performed at certain reaction times (from 0.5 to $20 \mathrm{~h}$ ) to check the formation of 1(3)-MAG and 2-MAG isomers. The FA profile of 1(3)-MAG and 2-MAG fractions at $8 \mathrm{~h}$ of reaction time was known by extraction of the appropriate band and the subsequent methylation for the FAME analysis in GC (data not shown). The results showed that the majority of EPA is 

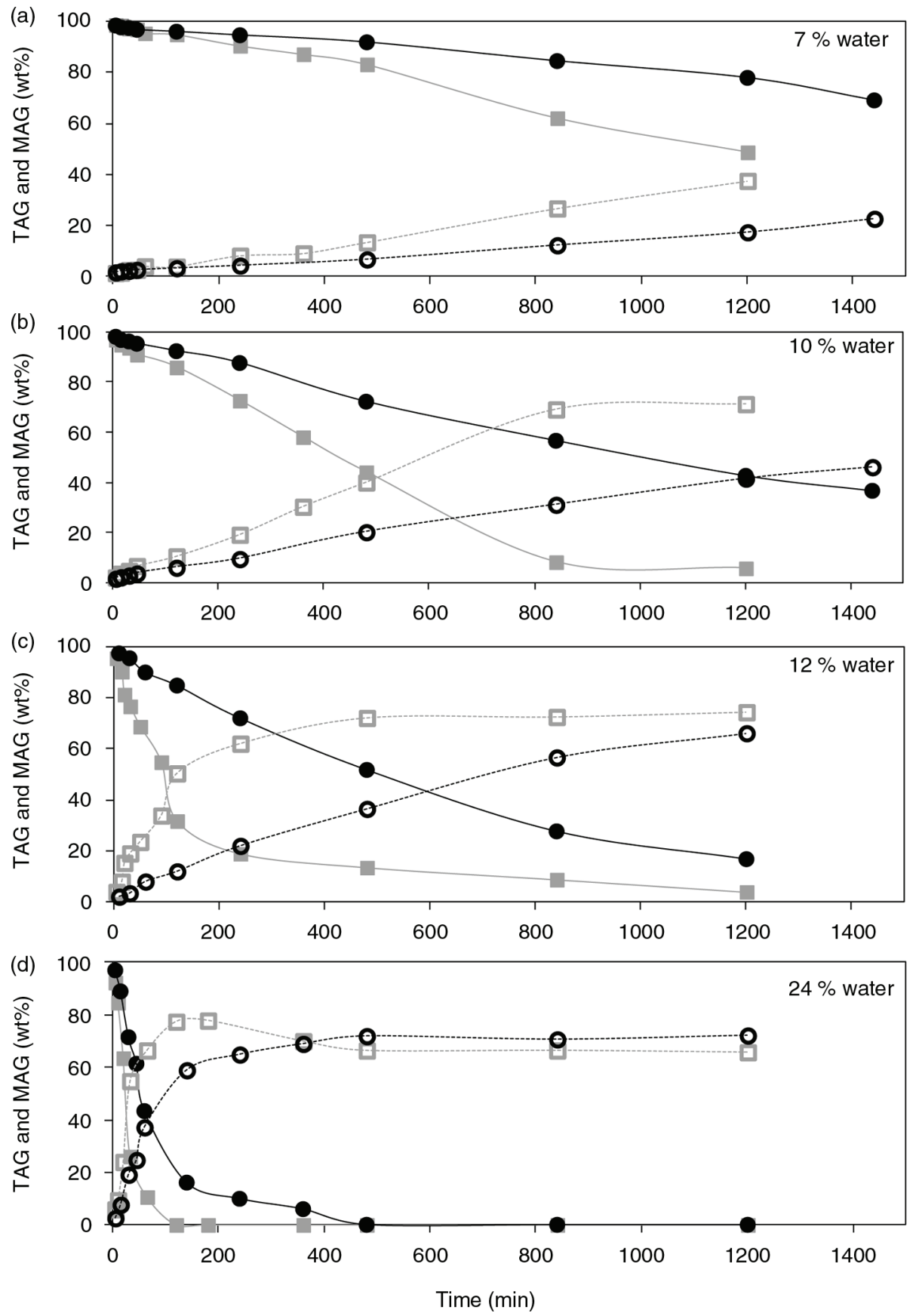

FIGURE 4. Effect of solvent type and water content on the time course of glycerolysis of sardine oil at different amounts of water in TP (grey lines) and in TB (black lines). (a) $7 \mathrm{wt} \%$, (b) $10 \mathrm{wt} \%$, (c) $12 \mathrm{wt} \%$, (d) $24 \mathrm{wt} \%$. (-•-) TAG in

TB, (-o-) MAG in TB, (- -) TAG in TP, (- -$)$ MAG in TP. Reaction conditions: glycerol:oil=3:1 (mol/mol), $10 \mathrm{wt} \%$ Lipozyme RM IM (based on oil and glycerol), $50{ }^{\circ} \mathrm{C}$.

found as 1(3)-MAG, while DHA is found mainly in 2-MAG. These outcomes are in agreement with the FA at the sn-2 position in the TAG (Table 3). In any case, acyl-migration could take place due to the positive surface charge of the support material, Duolite 568, the water added and the solvent medium (Fureby et al., 1996).

\section{CONCLUSIONS}

In this work, the glycerolysis of sardine oil in two different tert-alcohols (TP and TB) as reaction medium has been performed. The amount of solvent added has been optimized to ensure the homogeneity of the reaction medium. The 1,3 

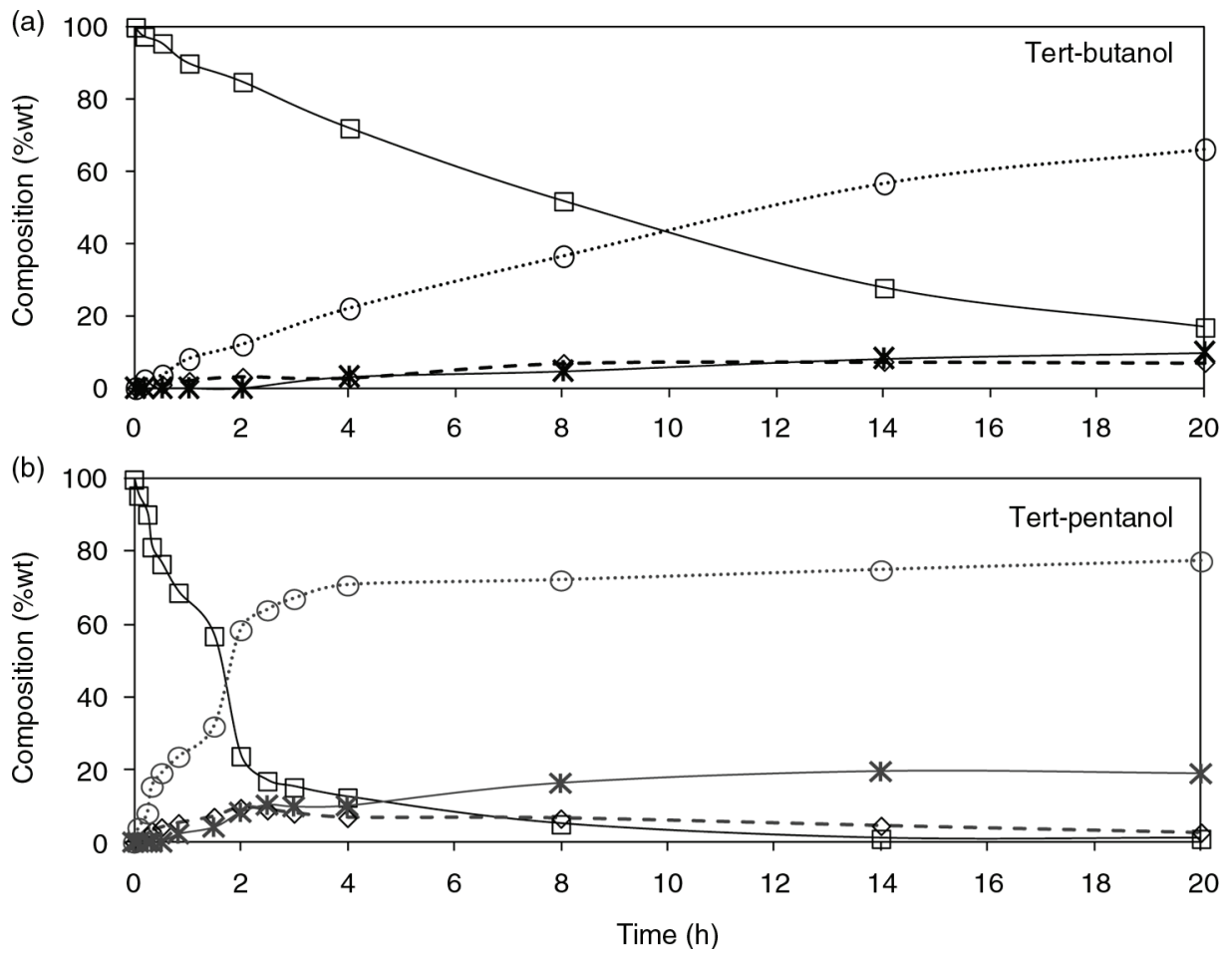

FIgURE 5. Time course of glycerolysis of sardine oil under optimal conditions: glycerol/oil=3:1 (mol/mol), $10 \mathrm{wt} \%$ Lipozyme RM IM (based on oil and glycerol), $50{ }^{\circ} \mathrm{C}$ and $12 \%$ of water content in the glycerol. (a) in TB and (b) in TP. TAG (-口-), MAG (-o-), DAG (-৩-) and FFA (-x-).

TABLE 3. Fatty acid composition of sardine oil and at the sn- $2^{\mathrm{a}}$ position of TAG (\% mol) (Solaesa et al., 2014). Fatty acid composition of MAG fractions after NP-HPLC separation under optimal reaction conditions ( $\% \mathrm{~mol})$.

\begin{tabular}{|c|c|c|c|c|c|c|c|}
\hline \multirow[b]{2}{*}{ Fatty acid } & & \multicolumn{2}{|c|}{ Sardine oil } & \multicolumn{2}{|c|}{ TP medium } & \multicolumn{2}{|c|}{ TB medium } \\
\hline & & TAG & $s n-2^{\mathrm{a}}$ & $4 h(70 \%)$ & $20 \mathrm{~h}(77 \%)$ & $4 h(22 \%)$ & $20 \mathrm{~h}(66 \%)$ \\
\hline Myristic (M) & $14: 0$ & 12.4 & 41.8 & $12.2 \pm 0.3$ & $12.0 \pm 0.2$ & $12.3 \pm 0.5$ & $11.9 \pm 0.5$ \\
\hline Palmitic (P) & $16: 0$ & 22.8 & 41.9 & $25.2 \pm 0.3$ & $25.1 \pm 0.1$ & $27.1 \pm 0.6$ & $25.6 \pm 0.2$ \\
\hline Palmitoleic (Po) & $16: 1 n-7$ & 12.5 & 38.1 & $13.4 \pm 0.3$ & $12.6 \pm 0.2$ & $13.5 \pm 0.1$ & $13.3 \pm 0.2$ \\
\hline Stearic (S) & $18: 0$ & 3.6 & 6.7 & $4.4 \pm 0.4$ & $4.3 \pm 0.1$ & $6.0 \pm 0.2$ & $4.6 \pm 0.1$ \\
\hline Oleic $(\mathrm{O})$ & $18: 1 n-9$ & 9.8 & 16.6 & $12.3 \pm 0.3$ & $11.5 \pm 0.3$ & $15.3 \pm 0.3$ & $12.4 \pm 0.5$ \\
\hline Vaccenic (V) & $18: 1 \mathrm{n}-7$ & 3.7 & 10.1 & $4.3 \pm 0.2$ & $4.1 \pm 0.1$ & $5.0 \pm 0.1$ & $4.3 \pm 0.1$ \\
\hline Linoleic (Lo) & $18: 2 n-6$ & 2.5 & 32.7 & $3.0 \pm 0.2$ & $2.7 \pm 0.1$ & $3.6 \pm 0.7$ & $3.0 \pm 0.1$ \\
\hline Linolenic (Ln) & $18: 3 n-3$ & 1.0 & 29.0 & $1.1 \pm 0.1$ & $1.0 \pm 0.1$ & $1.2 \pm 0.1$ & $1.1 \pm 0.1$ \\
\hline Steriadonic (St) & $18: 4 n-3$ & 3.3 & 26.4 & $1.9 \pm 0.2$ & $2.5 \pm 0.2$ & $1.1 \pm 0.1$ & $1.8 \pm 0.1$ \\
\hline Eicosatrienoic (Et) & $20: 3 n-3$ & 1.3 & 19.6 & $1.0 \pm 0.1$ & $1.2 \pm 0.1$ & $0.7 \pm 0.1$ & $1.0 \pm 0.1$ \\
\hline Eicosapentaenoic (Ep) & $20: 5 n-3$ & 18.3 & 12.1 & $14.4 \pm 0.3$ & $15.5 \pm 0.2$ & $10.1 \pm 0.2$ & $14.3 \pm 0.2$ \\
\hline Docosapentaenoic (Dp) & $22: 5 n-3$ & 1.8 & 76.4 & $1.7 \pm 0.1$ & $1.8 \pm 0.1$ & $1.1 \pm 0.1$ & $1.7 \pm 0.1$ \\
\hline Docosahexaenoic (Dh) & $22: 6 n-3$ & 7.0 & 82.8 & $5.1 \pm 0.2$ & $5.7 \pm 0.2$ & $3.0 \pm 0.1$ & $5.0 \pm 0.2$ \\
\hline
\end{tabular}

(a) $\% s n-2=[\mathrm{mol} \% s n-2$ fatty acid $/(\mathrm{mol} \%$ fatty acid in TAG·3) $] \cdot 100$

specific lipase Lipozyme RM IM has been used as catalyst. This enzyme has been proved to be water dependent in this glycerolysis system, showing no activity without water and a maximum in the MAG production when adding around $12 \%$ water, based on glycerol, at a mole ratio glycerol:oil of $3: 1$. A high content of MAG, up to $70 \mathrm{wt} \%$, can be reached for both tert-alcohols, with a low FFA content. 


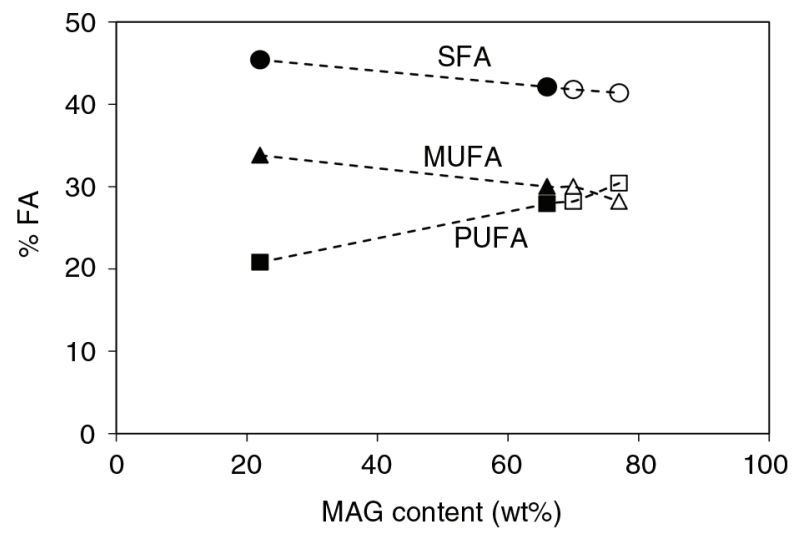

FIGURE 6. Evolution of the different types of FA in the MAG fraction according to the conversion degree. Black symbols represent reaction with TB and white symbols with TP. SFA $(-\bullet-)$ or (-०-), MUFA (- -) or (- $\left.\rangle_{-}\right)$and PUFA (-口-) or (-口-).

Furthermore, the fatty acid profile of 1(3)-MAG and 2-MAG fractions show that the original FA at the sn-2 position in the TAG is preserved, finding the majority of DHA as 2-MAG.

This research could be an economical alternative to take advantage of by-products of marine oils rich in PUFA. However, further work must be done to purify the MAG derivatives rich in PUFA due to their health benefits to be used in the pharmaceutical and food industries.

\section{ACKNOWLEDGEMENTS}

The authors acknowledge the Spanish Government through MINECO and the European Regional Development Fund (ERDF) for financial support to the project CTQ2012-39131-C02-01. They wish to thank Novozymes A/S for kindly supplying the enzymes. RM acknowledges MINECO for an FPI grant (reference BES-2013-063937). SLB acknowledges Mexican Secretariat of Public Education and Technological University of Morelia for a fellowship through PROMEP program. AGS acknowledges University of Burgos for a fellowship.

\section{REFERENCES}

AOAC Official Method 991.39. Fatty Acids in Encapsulated Fish Oils and Fish Oil Methyl and Ethyl Esters. 1995.

Blanco M, Sotelo CG, Chapela MJ, Pérez-Martín RI. 2007. Towards sustainable and efficient use of fishery resources: present and future trends. Trends Food Sci. Tech. 18, 29-36. http://dx.doi.org/10.1016/j.tifs.2006.07.015.

Bornscheuer UT. 1995. Lipase-catalyzed syntheses of monoacylglycerols. Enzyme Microb. Technol. 17, 578-586. http:// dx.doi.org/10.1016/0141-0229(94)00096-A.

Cheirsilp B, Kaewthong W, H-Kittikun A. 2007. Kinetic study of glycerolysis of palm olein for monoacylglycerol production by immobilized lipase. Biochem. Eng. J. 35, 71-80. http:// dx.doi.org/10.1016/j.bej.2006.12.024.

Damstrup ML, Jensen T, Sparsø FV, Kiil SZ, Jensen AD, Xu X. 2005. Solvent optimization for efficient enzymatic monoacylglycerol production based on a glycerolysis reaction. $\mathrm{J}$. Am.
Oil Chem. Soc. 82, 559-564. http://dx.doi.org/10.1007/ s11746-005-1109-y.

Feltes MMC, de Oliveira D, Block JM, Ninow JL. 2013. The Production, Benefits, and Applications of Monoacylglycerols and Diacylglycerols of Nutritional Interest. Food Bioprocess Tech 6, 17-35. http://dx.doi.org/10.1007/s11947-012-0836-3.

Fregolente PBL,Fregolente LV, Pinto GMF, Batistella BC, WolfMaciel MR, Filho RM. 2008. Monoglycerides and diglycerides synthesis in a solvent-free system by lipase-catalyzed glycerolysis. Appl. Biochem. Biotechnol. 146, 165-172. http:// dx.doi.org/10.1007/s12010-008-8133-3.

Fureby AM, Virto C, Adlercreutz P, Mattiasson B. 1996. Acyl group migrations in 2-monoolein. Biocatal. Biotransform. 14, 89-111. http://dx.doi.org/10.3109/10242429609106879.

Hernandez EM. 2014. Issues in fortification and analysis of omega-3 fatty acids in foods. Lipid Technol. 26, 103-106. http://dx.doi.org/10.1002/lite.201400004

Jin J, Li D, Zhu XM, Adhikari P, Lee K-T, Lee J-H. 2011. Production of diacylglycerols from glycerol monooleate and ethyl oleate through free and immobilized lipase-catalyzed consecutive reactions. New Biotechnol. 28, 190-195. http:// dx.doi.org/10.1016/j.nbt.2010.10.005.

Kim SK, Mendis E. 2006. Bioactive compounds from marine processing byproducts - A review. Food Res. Int. 39, 383-393. http://dx.doi.org/10.1016/j.foodres.2005.10.010.

Kristensen JB, Xu X, Mu H. 2005. Diacylglycerol synthesis by enzymatic glycerolysis: Screening of commercially available lipases. J. Am. Oil Chem. Soc. 82, 329-334. http:// dx.doi.org/10.1007/s11746-005-1074-5.

Krüger RL, Valério A, Balen M, Ninow JL, Oliveira JV, de Oliveira D, Corazza ML. 2010. Improvement of mono and diacylglycerol production via enzymatic glycerolysis in tert-butanol system. Eur. J. Lipid Sci. Technol. 112, 921-927. http://dx.doi. org/10.1002/ejlt.200900253

Majid N, Cheirsilp B. 2012. Optimal conditions for the production of monoacylglycerol from crude palm oil by an enzymatic glycerolysis reaction and recovery of carotenoids from the reaction product. Int. J. Food Sci. Technol. 47, 793-800. http://dx.doi.org/10.1111/j.1365-2621.2011.02909.x.

Nichols PD, McManus A, Krail K, Sinclair AJ, Miller M. 2014 Recent advances in omega-3: Health benefits, Sources, Products and bioavailability. Nutrients. 6, 3727-3733. http://dx.doi.org/10.3390/nu6093727.

Pawongrat R, Xu X, H-Kittikun A. 2008. Physico-enzymatic production of monoacylglycerols enriched with very-long-chain polyunsaturated fatty acids. J. Sci. Food Agric. 88, 256-262. http://dx.doi.org/10.1002/jsfa.3081.

Rendón X, López-Munguía A, Castillo E. 2001. Solvent engineering applied to lipase-catalyzed glycerolysis of triolein. J. Am. Oil Chem. Soc. 78, 1061-1066. http://dx.doi.org/10. 1007/s11746-001-0389-6.

Riddick JA, Bunger WB, Sakano TK. 1986. Organic Solvents, Physical Properties and Methods of Purification. Wiley. New York.

Sidhu KS. 2003. Health benefits and potential risks related to consumption of fish or fish oil. Regul. Toxicol. Pharm. 38, 336-344. http://dx.doi.org/10.1016/j.yrtph.2003.07.002.

Singh AK, Mukhopadhyay M. 2012. Olive oil glycerolysis with the immobilized lipase Candida antarctica in a solvent free system. Grasas Aceites. 63, 202-208. http://dx.doi.org/ 10.3989/gya.094811

Solaesa ÁG, Bucio SL, Sanz MT, Beltrán S, Rebolleda S. 2013. Liquid-liquid equilibria for systems glycerol + sardine oil + tert-alcohols. Fluid Phase Equilib. 356, 284-290. http:// dx.doi.org/10.1016/j.fluid.2013.07.026.

Solaesa ÁG, Bucio SL, Sanz MT, Beltrán S, Rebolleda S. 2014. Characterization of Triacylglycerol Composition of Fish Oils by Using Chromatographic Techniques. J. Oleo Sci. 63, 449-460. http://dx.doi.org/10.5650/jos.ess 13202 .

Torres C, Lin B, Hill Jr CG. 2002. Lipase-catalyzed glycerolysis of an oil rich in eicosapentaenoic acid residues. Biotechnol. Lett. 24, 667-673. http://dx.doi.org/10.1023/A:1015298728683.

Voll F, Krüger RL, de Castilhos F, Filho LC, Cabral V, Ninow J, Corazza ML. 2011. Kinetic modeling of lipase-catalyzed glycerolysis of olive oil. Biochem. Eng. J. 56, 107-115. http:// dx.doi.org/10.1016/j.bej.2010.11.005. 
Weber N, Mukherjee KD. 2004. Solvent-free lipase-catalyzed preparation of diacylglycerols. J. Agric. Food Chem. 52, 5347-5353. http://dx.doi.org/10.1021/jf0400819.

Wongsakul S, Prasertsan P, Bornscheuer UT, H-Kittikun A. 2003. Synthesis of 2-monoglycerides by alcoholysis of palm oil and tuna oil using immobilized lipases. Eur. J. Lipid Sci. Technol. 105, 68-73. http://dx.doi.org/10.1002/ejlt.200390019.

$\mathrm{Xu}$ X. 2000. Production of specific-structured triacylglycerols by lipase-catalyzed reactions: a review. Eur. J. Lipid Sci. Technol. 102, 287-303.

$\mathrm{Xu}$ X. 2003. Engineering of enzymatic reactions and reactors for lipid modification and synthesis. Eur. J. Lipid Sci. Technol. 105, 289-304. http://dx.doi.org/10.1002/ejlt.200390059.

Yang T, Rebsdorf M, Engelrud U, Xu X. 2005a. Enzymatic production of monoacylglycerols containing polyunsaturated fatty acids through an efficient glycerolysis system. J. Agric. Food Chem. 53, 1475-1481. http://dx.doi.org/10.1021/jf048405g.

Yang T, Rebsdorf M,Engelrud U, Xu X. 2005b. Monoacylglycerol synthesis via enzymatic glycerolysis using a simple and efficient reaction system. J. Food Lipids. 12, 299-312. http:// dx.doi.org/10.1111/j.1745-4522.2005.00025.x.

Yeoh CM, Choong TSY, Abdullah LC, Yunus R, Siew WL. 2009. Influence of silica gel in production of diacylglycerol via enzymatic glycerolysis of palm olein. Eur. J. Lipid Sci. Technol. 111, 599-606. http://dx.doi.org/10.1002/ejlt. 200800265

Zhong N, Li L, Xu X, Cheong L, Li B, Hu S, Zhao X. 2009. An Efficient Binary Solvent Mixture for Monoacylglycerol Synthesis by Enzymatic Glycerolysis. J. Am. Oil Chem. Soc. 86, 783-789. http://dx.doi.org/10.1007/s11746-009-1402-7. 